\title{
Der deutsche Verwaltungsrechtsschutz unter dem Einfluss der Aarhus-Konvention
}

Zugleich ein Beitrag zur Fortentwicklung der subjektiven öffentlichen Rechte unter besonderer Berücksichtigung des Gemeinschaftsrechts

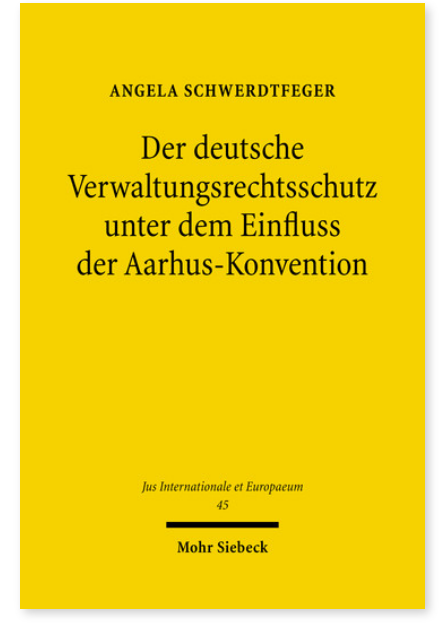

2010. XXVI, 351 Seiten. JusIntEu 45

ISBN 978-3-16-151184-4

DOI 10.1628/978-3-16-151184-4

eBook PDF 89,00€

ISBN 978-3-16-150423-5

fadengeheftete Broschur 89,00€
Das »Übereinkommen über den Zugang zu Informationen, die Öffentlichkeitsbeteiligung an Entscheidungsverfahren und den Zugang zu Gerichten in Umweltangelegenheiten«, die sog. Aarhus-Konvention, sieht das Recht von Einzelnen und Umweltverbänden auf einen weiten Zugang zu Gerichten in Umweltangelegenheiten vor. Damit stellt es das deutsche Verwaltungsrecht vor beachtliche Herausforderungen, ist dieses doch durch strenge Zugangsvoraussetzungen und eine vergleichsweise geringe Bedeutung des Verfahrensrechts geprägt. Angela Schwerdtfeger untersucht, inwieweit die Anforderungen des völkerrechtlichen Vertrages und des zu seiner Umsetzung ergangenen europäischen Richtlinienrechts im System des deutschen subjektiven Rechtsschutzes dogmatisch umgesetzt werden können. Dabei geht sie auch der Frage nach, ob das Umwelt-Rechtsbehelfsgesetz den völker- und europarechtlichen Vorgaben ausreichend gerecht wird.

Angela Schwerdtfeger Geboren 1980; Studium der Rechtswissenschaft in Trier und Lyon; 2006 erstes juristisches Staatsexamen; 2009 Promotion; 2010 zweites juristisches Staatsexamen; 2017 Habilitation.
Jetzt bestellen:
https://mohrsiebeck.com/buch/der-deutsche-verwaltungsrechtsschutz-unter-dem-einfluss-der-aarhus-konvention-
9783161511844?no_cache=1
order@mohrsiebeck.com
Telefon: +49 (0)7071-923-17
Telefax: +49 (0)7071-51104 